(4) थ/Ascofapsi

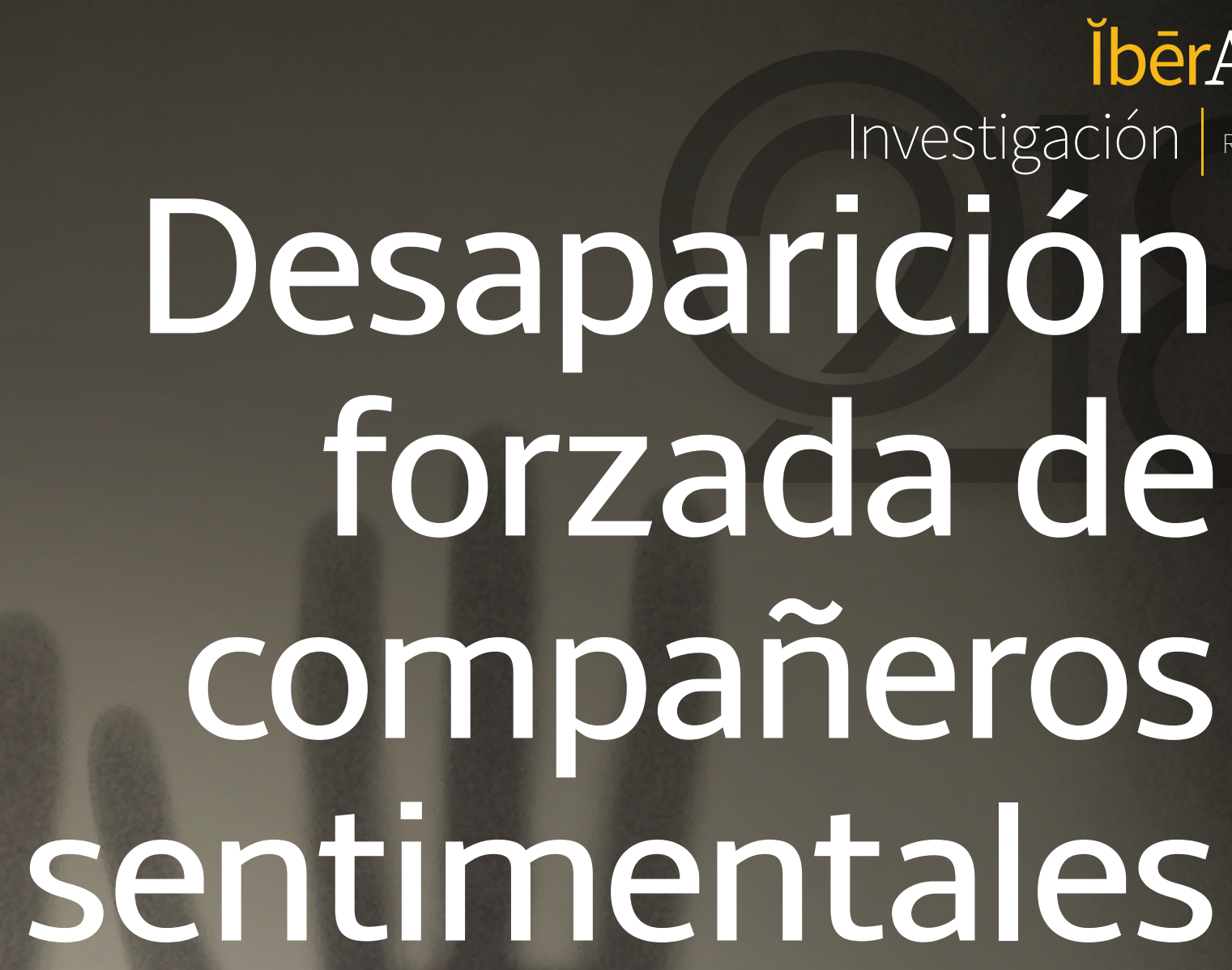

Significado del proceso de reparación en dos mujeres

Enforced disappearance of sentimental partners: meaning of the reparation process in two women
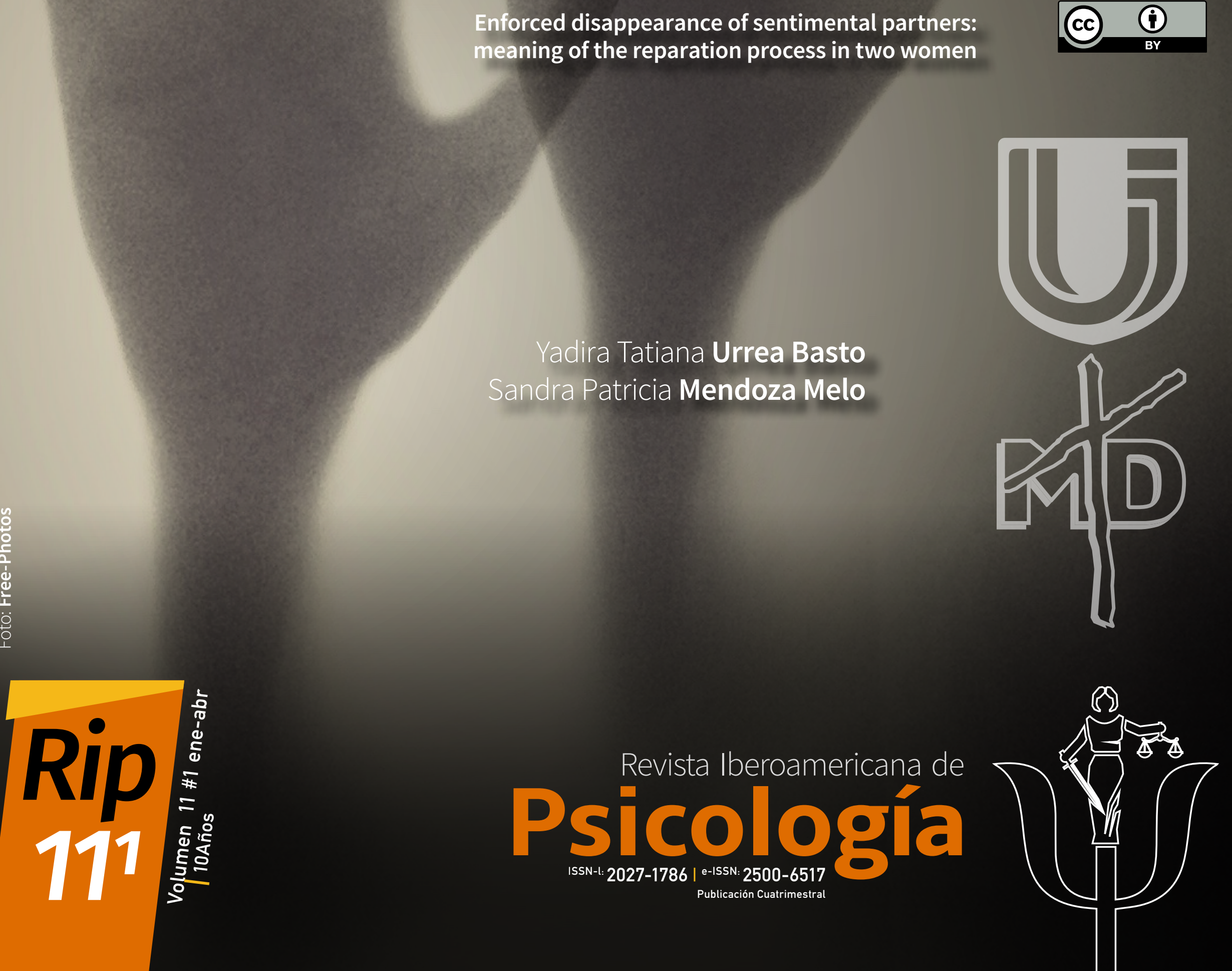
Revista Iberoamericana de

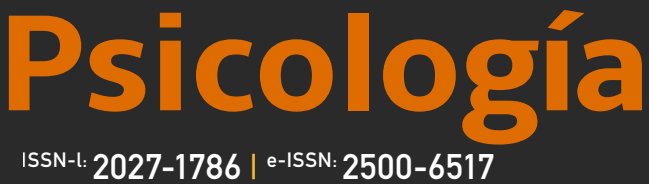
Publicación Cuatrimestral

ID:

\section{7-1786.rip.11104}

Title: $\quad$ Enforced disappearance of sentimental partners

Subtitle: Meaning of the reparation process in two women

Título: Desaparición forzada de compañeros sentimentales

Subtítulo: Significado del proceso de reparación en dos mujeres

Alt Title / Título alternativo:

[en]: $\quad$ Meaning of the reparation process for two women who are victims of the forced disappearance of their sentimental partners

[es]: $\quad$ Significado del proceso de reparación para dos mujeres víctimas de la desaparición forzada de sus compañeros sentimentales

Author (s) / Autor (es):

\section{Urrea Basto, \& Mendoza Melo}

Keywords / Palabras Clave:

human rights; forced disappearance; reparation; victim

derechos humanos; desaparición forzada; reparación; víctima

Submited: 2017-11-09

Acepted: 2017-12-22

\section{Resumen}

La desaparición forzada es un crimen que

trasciende en el tiempo, que vulnera los derechos de muchas familias en Colombia y afecta a diferentes poblaciones, entre estas

mujeres quienes sufren por la desaparición de sus compañeros sentimentales. El objetivo de esta investigación es analizar el significado que tiene el proceso de reparación para dos mujeres víctimas de la desaparición forzada de sus compañeros sentimentales. Las participantes fueron dos (2) mujeres víctimas de este delito, residentes en la ciudad de Bogotá y Valledupar. La recolección de datos se desarrolló a partir de la investigación biográfico-narrativa, a partir de la historia de vida de estas mujeres, tomando como punto

de partida las categorías preestablecidas e identificando categorías emergentes a partir de su relato. Entre las consecuencias que trajo la desaparición de sus compañeros destaca el daño producido en sus proyectos de vida,

el impacto repentino que éstos sufrieron, y

la destrucción de los objetivos que habían sido construidos desde la cotidianidad en pareja, lo cual afecta, por consiguiente, todas

las áreas de sus vidas. Adicionalmente, la desaparición forzada de sus parejas ocasionó un cambio de roles al interior de sus familias y una ruptura del tejido social. Resulta preciso mencionar que se evidencia en estas mujeres desconocimiento de sus derechos.

Yadira Tatiana Urrea Basto, MA Psi

$$
\text { ORCID: } \quad \text { 0000-0003-2350-4474 }
$$

\section{Source | Filiacion:}

Corporación Universitaria Iberoamericana

BIO:

Psicologa

Magister En Psicologia Juridica

\section{City | Ciudad:}

Bogotá DC [co]

e-mail:

yadira.urrea@iberoamericana.edu.co

\section{Abstract}

Forced disappearance is a crime that transcends time, which violates the rights of many families in Colombia and affects many populations (including women who suffer for the loss of their sentimental couples). The objective of this research is to understand what the meaning of the reparation process is for women who are victims of the forced disappearance of their couples. The participants were two (2) women victims of this crime who live in Bogota and Valledupar. Data collection was carried out based on the biographical-narrative research, parting from the story of these women, specifically the pre-established categories and identifying

emerging categories in their discourse.

Among the consequences brought by the disappearance of their couples highlights the damage upon their life projects, the sudden impact to these projects, and the destruction of the objectives that had been constructed

from everyday life as a couple, due to the imposition of the armed actors of the conflict, which thus affects all areas of their lives. Additionally, the forced disappearance of their couples caused a change in the roles within

their family as well as a breakdown of the social fabric. It is worth mentioning that these women show a lack of knowledge regarding their rights.
Sandra Patricia Mendoza Melo, Psi

ORCID: $\quad$ 0000-0003-2413-3759

\section{Source | Filiacion:}

Uniminuto, Corporación Universitaria Minuto de Dios

BIO:

Psicologa

City | Ciudad:

Bogotá DC [Co]

e-mail:

sandrapmendozauniminuto@gmail.com

Citar como:

Urrea Basto, Y. T., \& Mendoza Melo, S. P. (2018). Desaparición forzada de compañeros sentimentales: Significado del proceso de reparación en dos mujeres. Revista Iberoamericana de Psicología issn-l:2027-1786, 11 (1), 33-44 Obtenido de: https://revistas.iberoamericana.edu.co/index.php/ripsicologia/article/view/1294 


\title{
Desaparición forzada de compañeros sentimentales Significado del proceso de reparación en dos mujeres
}

\author{
Enforced disappearance of sentimental partners: \\ meaning of the reparation process in two women \\ Yadira Tatiana Urrea Basto \\ Sandra Patricia Mendoza Melo
}

\section{Introducción}

Muchas de las víctimas de los cincuenta (50) años de violencia que sufrió Colombia son víctimas del asesinato selectivo, un tipo de violencia sistemática caracterizada por la desaparición forzada y un dispositivo de terror que no sólo afectó a los opositores del Estado sino también a grupos sociales en condiciones de vulnerabilidad -entre otros-, para quienes tal vivencia se tornó común. Amnistía Internacional (2008) y la Convención Internacional para la Protección de Todas las Personas contra la Desaparición Forzada de la Organización de las Naciones Unidas (ONU, 2005) coinciden en definir esta práctica como una violación de derechos humanos especialmente cruel que afecta tanto a la persona desaparecida como a su familia y amistades. De acuerdo al Sistema de Información Red de Desaparecidos y Cadáveres (SIRDEC) (INMLCF, s.f.), entre el 7 de agosto de 2010 y el 10 de noviembre de 2011 se registraron 287 personas desaparecidas de manera forzada, de las cuales 223 siguen desaparecidas.

Estas cifras indican que en Colombia existe un alto número de víctimas, las cuales de acuerdo a la información suministrada por el Observatorio de Derechos Humanos y Derecho Humanitario, en la Mesa de Trabajo sobre Desaparición Forzada (Gráfico 1) se discriminan de la siguiente manera: el $\mathbf{4 6 . 1 \%}$ corresponde a personas campesinas, le siguen estudiantes (14.8\%), líderes sociales y comunitarios $(\mathbf{7 . 8 \%})$, educadores (4.7\%), defensores de Derechos Humanos (3.9\%), militantes de algún partido político (3.9\%) y sindicalistas (0.8\%).

De acuerdo a la Organización de Naciones Unidas (2005), se considera víctima a toda persona que haya sufrido daños emocionales o físicos, siendo afectados sus derechos fundamentales. Dentro del Derecho Internacional Humanitario se considera como víctima a la familia tanto nuclear como extensa, a las personas a cargo de la víctima, así como a las personas quienes hayan sufrido daños al intervenir para prestar asistencia a víctimas en peligro o para impedir la victimización. Ésta última definición ha de ser de especial relevancia para Colombia pues a lo largo de su historia la atención se ha centrado más en las víctimas directas (las personas desaparecidas) que en las

víctimas indirectas (por ejemplo las familias, que sufren también las consecuencias de la desaparición) y, como lo señala Beristain (2010), en casos de desaparición forzada los familiares también sufren sus propias violaciones de derechos humanos, especialmente del derecho a la verdad, a la justicia y/o al duelo. Además, una vez desaparecida la persona son los familiares quienes deben asumir las consecuencias económicas, físicas y psicológicas que se presentan en los contextos familiar y comunitario, dado que los roles que ejercían quienes desaparecen quedan como herencia a sus familiares más cercanos y son asumidos sin derecho a renunciar a estos.

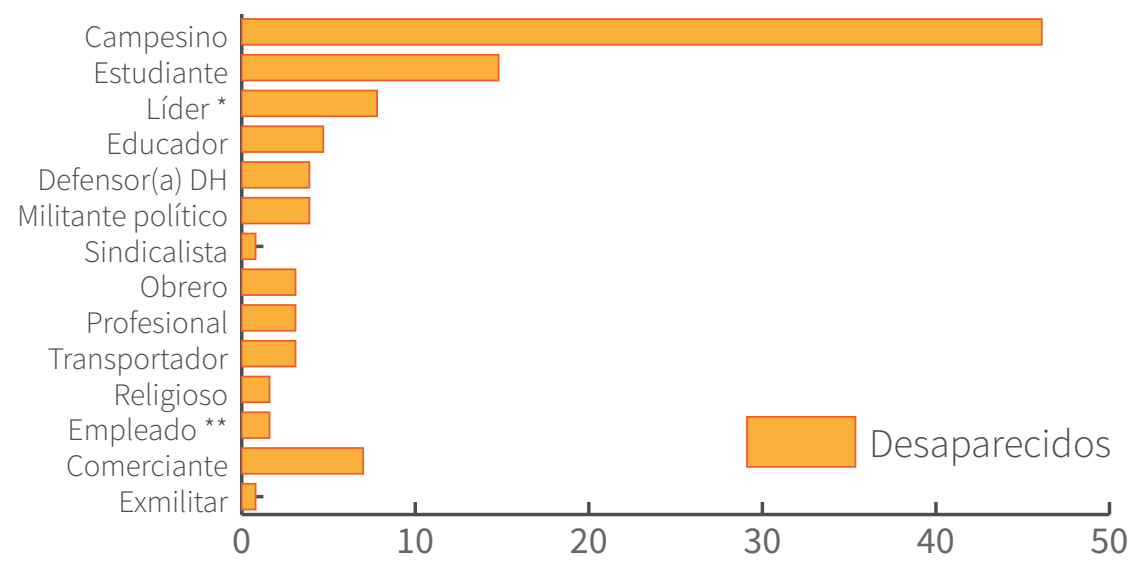

Gráfico 1 Casos de Desaparición Forzada entre 1980 y 2011

*: comunal, campesino, estudiantil, político; **: privado o público; Por profesión o actividad de la víctima. Desapariciones forzadas en Colombia. En búsqueda de la justicia. (Documentos temáticos n. ${ }^{\circ} 6$ ) (2012). Mesa de trabajo sobre Desaparición Forzada de la Coordinación Colombia-Europa-Estados

Unidos Bogotá. Observatorio de derechos humanos y derecho humanitario.

Respecto al profundo impacto psicosocial que las desapariciones forzadas tienen sobre las víctimas directas, el entorno familiar y social, destacan la angustia y la incertidumbre frente al paradero del ser querido desaparecido, así como el dolor. Tal cual especifica Cabanillas (2005), la desaparición forzada provoca un daño psicológico particular en los familiares de las víctimas, el cual atiende a determinados periodos tras la desaparición:

a. la retención, primer período en que los familiares son testigos de 
la retención de su ser querido, lo que les provoca una sensación de inseguridad

b. la búsqueda, segundo período durante el que la familia conserva la esperanza que su familiar esté con vida por lo que se asume una ausencia temporal y no una pérdida definitiva. Dado que el tiempo de ausencia de la víctima se prolonga, toma lugar un proceso de reestructuración de roles afectivos y económicos en el que la mujer se enfrenta a la decisión de garantizar el sustento para su familia o continuar con la búsqueda de su ser querido

c. aceptación de la desaparición, tercer período caracterizado por el deterioro de vínculos al interior de la familia de la víctima debido a la estigmatización y el distanciamiento de los familiares más cercanos causados por el temor a correr la misma suerte del desaparecido. Por lo anterior la ausencia de redes de apoyo en la familia es más evidente

d. posibilidad de muerte, cuarto periodo en el que se genera un gran sentido de pérdida y un período prolongado de duelo.

Según Cabrera (2006), la relación entre las vivencias asociadas a una situación de crisis (trauma) y el contexto socio histórico en que ésta se produce, permite identificar las formas de vivir el duelo. Gómez (2006) define el duelo como un proceso mediante el cual una persona enfrenta pérdidas y separaciones, sin embargo, en casos de desaparición forzada dicho proceso se ve alterado en tanto las manifestaciones de dolor son prohibidas y coartadas por los actores intelectuales y materiales de este delito, y la imposibilidad de conocer la localización de la persona desaparecida o sus restos imposibilitan el desarrollo de rituales como la misa e inhumación. Como afirma Gómez (2006), cuando las familias no pueden desarrollar los procesos de duelo presentan dificultades para adaptarse a la realidad, lo que sin duda aumenta su dolor.

Por otra parte, la magnitud de este daño psicológico es tan grande que se habla de daño transgeneracional, como su nombre lo indica se trata de un daño que atraviesa varias generaciones. Scapusio (2006) lo define como:

Todo tipo de afectación o menoscabo a la integridad física de las personas y a la trama social que las sustenta. A la alteración y eliminación deliberada- utilizando la fuerza y el poder-de un devenir potencialmente productivo de lo individual y lo colectivo en el que se conjugan y enlazan los destinos personales y sociales.

(Scapusio, 2006, pág. 2)

SegúnBiedermann(2009),esteconceptodedañotransgeneracional, empieza a desarrollarse hacia los años cincuenta cuando el Estado alemán indemnizó a las víctimas del Holocausto. Posteriormente, en los años sesenta se identificaron síntomas específicos en los hijos adultos de sobrevivientes del Holocausto que no eran hallados en otro tipo de población. Una investigación desarrollada por Rakoff, Sigal y Epstein (1966) reveló cómo el trauma incidía negativamente en los hijos de las víctimas, generando determinadas reacciones desadaptativas y considerables trastornos mentales. En un estudio llevado a cabo por Bastidas, Rodríguez, y Soto (2001) con personas afectadas por el terrorismo de Estado durante la dictadura en Chile, evidenciaron que el trauma generado por hechos violentos genera patrones relacionales dentro de la estructura familiar generando una tendencia a manejar de manera rígida la forma de relacionarse entre los miembros de estas familias y esto afecta a las generaciones sucesivas. Por último, Díaz (2012) identifica en su estudio diferencias significativas entre mujeres y hombres:

\section{Encontrándose un mayor impacto de la} transgeneracionalidad en las mujeres, donde se destaca una mayor función de protección hacia los padres, mayor privatización del daño, con dificultades para hablary distancia emocional. También está presente una mayor disfunción interpersonal y miedo al abandono. Además, se aprecia una mayor vulnerabilidad al estrés en los componentes cognitivos y tensional, con una tendencia en la vulnerabilidad general y en los componentes somáticos". (Díaz, 2012, pág. 98)

Los estudios citados aportan comprensión en torno a las afectaciones que generan las represiones políticas en sus distintas modalidades (entre estas la desaparición forzada de personas durante las dictaduras) específicamente el daño transgeneracional, que no sólo afecta los procesos individuales de cada sujeto y el propósito de su existencia, sino también en los procesos sociales. Además, destaca el impacto psicológico que produce la desaparición forzada empleada por varios actores (Estado, paramilitares, guerrilla, bandas criminales y grupos al margen de la ley) como un mecanismo de dominación político y económico.

En consonancia con lo anterior, Martin Baró (1990, citado por Madariaga, 2003) en su dialéctica sujeto individual/sujeto social afirma que los hechos acontecidos durante la dictadura militar tienen su génesis en un contexto político y en las relaciones sociales, por lo que las raíces del trauma están dadas en el aspecto social y no sólo en los procesos intrapsíquicos del individuo. Así pues, la identidad de cada sujeto no se define por los enfrentamientos que tiene con los otros, "[T] ambién está marcada... por las huellas de los conflictos comunes y de los accidentes singulares que marcaron la vida de los padres, de los abuelos, de los colaterales y de los amigos. (Tisseron, 1995, citado en Citras, 2009, pág. 49).

Diferentes estudios indican la necesidad de distinguir la realidad que enfrentan tanto hombres como mujeres ante las trasgresiones de derechos. De acuerdo a las estadísticas suministradas por el Observatorio de Derechos Humanos (2012) de los casos de desaparición forzada registrados el $\mathbf{9 0 \%}$ corresponde a hombres ( $\mathbf{8 3 7}$ casos) y el $\mathbf{1 0 \%}$ a mujeres (66 casos), lo que muestra a las mujeres como sobrevivientes y víctimas de este flagelo. En el 2015 el Centro Internacional para la Justicia Transicional (ICTJ, 2015) publicó el informe: Las desaparecidas y las invisibles. Repercusiones de la desaparición forzada en las mujeres, en el que confirman que la víctima directa de este flagelo es por lo general el hombre sin dejar de reconocer la falta de denuncias de desaparición de mujeres. En este estudio también mencionan el desequilibrio familiar, social y económico y el rol distintivo de la mujer.

En consonancia con lo anterior, Mejía (2010), señala que en Colombia la violencia y el desplazamiento tienen efectos diferenciados sobre hombres y mujeres: frente a esta violencia las mujeres son más vulnerables en tanto son sometidas a mecanismos de violencia que afectan su dignidad, su derecho a la libertad y a la igualdad. Según las estadísticas, las víctimas de desaparición forzada son en su mayoría hombres, lo que genera un desequilibrio social y económico al interior de la familia y conlleva a que los roles establecidos cambien y sus compañeras se conviertan en el centro y sustento de la familia. (INMLCF, 2016).

Dicho rol o labor que desempeñan las mujeres incluye, entre otras cosas, ser la 'columna vertebral' en tanto deben encargarse en su totalidad de la educación de los hijos. Dado que estos núcleos familiares quedan, de alguna manera, en condiciones de vulnerabilidad por la ausencia de ese referente y apoyo familiar, las mujeres deben buscar más trabajo para suplir por sí solas las necesidades básicas, 
trabajo que en muchas ocasiones no es digno o bien remunerado, sin embargo, deben tomarlo para lograr sobrevivir en una sociedad que en ocasiones se torna indiferente ante su situación.

A lo anterior se añade el tener que convivir con el miedo y afrontar la incertidumbre de no saber el paradero del ser querido, en ocasiones quedar a la deriva y verse obligadas a desplazarse de manera forzada abandonando así a sus familiares, amigos y su entorno, para llegar a otros lugares como foráneas extrañas donde nadie comprende su dolor y donde se les trata con indiferencia.

La Constitución Política de Colombia establece en su Artículo 12: "Nadie será sometido a desaparición forzada, a torturas ni a tratos o penas crueles, inhumanas o degradantes" (1991), cuando este derecho es vulnerado el Estado inicia acciones para tratar de restablecer y reparar a las víctimas. Tales esfuerzos constituyen el proceso de reparación a víctimas que, entre otras cosas, fomenta espacios de interacción en los que éstas han encontrado oportunidades de participación, espacios que fomentan la escucha y visibilizan con mayor fuerza el daño físico y emocional sufridos a raíz de la violencia, espacios en los que paulatinamente se les ha ayudado a construir una conciencia como sujetos de derechos y en los que se construyen y emergen representaciones que dan cuenta de su realidad específica.

Desde este marco, el presente artículo tiene por objetivo averiguar el significado que tiene la reparación para dos mujeres víctimas de la desaparición forzada de sus compañeros sentimentales. Partiendo del hecho que cada víctima sigue su propio camino ante la violencia vivida, esta investigación se para desde un enfoque cualitativo, adopta un método de recolección de información biográfico-narrativo y se configura en un estudio de caso en la medida que pretende develar un contexto de vida, individual o grupal específico. Bolívar (2002) a partir de la historia de dos (2) mujeres víctimas de la desaparición forzada de sus compañeros sentimentales. Debido a lo anterior, se acude al Análisis del Discurso el cual atribuye especial importancia a las experiencias cotidianas y a las formas en que los argumentos y nociones sobre la realidad son construidas a partir del lenguaje, pues éste último se concibe como una manifestación de la interacción que toma lugar en los ámbitos sociales y que permite la comprensión de los significados de existencia para entender el mundo y sus relaciones.

El «discurso» puede comprenderse como un complejo conjunto de actos lingüísticos simultáneos y secuencialmente interrelacionados, actos que se manifiestan a lo largo y ancho de los ámbitos sociales de acción como muestras semióticas (orales, escritas y temáticamente interrelacionadas) y muy frecuentemente como «textos». (Wodaky Meyer, 2003, p.4).

En consonancia con lo anterior, dar sentido a la experiencia a partir del uso del discurso es entender a Potter \& Wetherell (1987) cuando afirman que "el lenguaje ordena nuestras percepciones y hace que las cosas sucedan, mostrando cómo el lenguaje puede ser usado para construir y crear la interacción social y diversos mundos sociales" (pág. 1).

Para lograr lo anteriormente propuesto, se deben tener en cuenta y analizar las desigualdades sociales y de género en las diferentes comunidades, abordando sus tradiciones, culturas y clases. En especial la mujer padece de manera diferente los efectos de la desaparición forzada, pues su rol dentro de la familia sufre un cambio abrupto, lo que la lleva a someterse a nuevas dinámicas que desconoce, poniendo en jaque su estabilidad económica, social, afectiva y mental, pues ellas quedan a cargo no sólo de los niños sino también de los adultos mayores quienes viven en estas familias. Esto significa que las desapariciones forzadas tienen un impacto específico sobre las mujeres que es consecuencia de la estructura de género de la Sociedad Colombiana (Observatorio de derechos humanos, 2012).

\section{Metodología}

Con el fin de identificar y comprender el significado que tiene la reparación para mujeres víctimas de la desaparición forzada de sus compañeros sentimentales, se acudió a dos (2) mujeres cabeza de familia víctimas del tipo de violencia anteriormente mencionado a través del Comité Permanente Para la Defensa de los Derechos humanos (CPDH) y el Movimiento de Crímenes de Estado (MOVICE). Estas mujeres residen en la ciudad de Bogotá, aunque provienen de otras ciudades del país, ellas accedieron al proceso de reparación de víctimas y su participación en el presente estudio fue de manera voluntaria

Las experiencias de las dos (2) participantes en el proceso de reparación fueron recopiladas a partir de entrevistas individuales. Posteriormente, se llevó a cabo un análisis de sus relatos, tomando como punto de partida unas categorías preestablecidas, categorías y subcategorías deductivas e identificando categorías emergentes en los mismos. Cisterna (2005) distingue entre categorías generales (que indican un tópico/tema en sí mismo) y subcategorías (que detallan dicho tópico/tema en micro-aspectos) y ambas pueden ser apriorísticas (construidas antes del proceso de recopilación de la información y que en este caso en particular corresponden a conceptos objetivadores) o emergentes (que surgen desde el levantamiento de referencia, en este caso a partir del relato de las participantes y corresponden a conceptos sensibilizadores) (Elliot, 1990). Así pues, las categorías y subcategorías construidas previamente fueron:

\section{Tabla 2 Categorías y subcategorías}

$\begin{array}{cc}\text { Categorías } & \text { Sub Categorías } \\ \text { Proceso de Reparación } & \text { Legal } \\ & \text { Psicológico/Cognitivo Emocional } \\ \text { Social/Redes de Apoyo } & \text { Biológico/Físico } \\ \text { Mujeres Víctimas } & \text { Psicológico/Cognitivo Emocional } \\ & \text { Legal } \\ \text { Desaparición Forzada } & \text { Social/Redes de Apoyo } \\ \text { Legal } & \text { Psicológico/Cognitivo Emocional } \\ \text { Social/Redes de Apoyo } \\ \text { Compañeros Sentimentales } & \text { Biológico/Físico } \\ \end{array}$

\section{Proceso de Reparación}

La lucha contra la impunidad y el derecho de las víctimas a obtener reparaciones por las violaciones de Derechos Humanos y Derecho Internacional Humanitario son áreas específicas que han sido precisadas recientemente en el marco del derecho internacional público. Se trata de dos campos específicos del derecho internacional que se desprenden del reconocimiento del sufrimiento de las víctimas y de la necesidad de hacer frente a hechos que ultrajan la conciencia de la humanidad. Tanto la lucha contra la impunidad como el derecho a obtener reparaciones se derivan de la obligación general de todos los Estados de respetar y hacer respetar los Derechos Humanos, concretamente son deberes estatales en materia de administración de justicia.

Específicamente, la reparación tiene como objeto aliviar el sufrimiento de la víctima y, en la medida de lo posible, restablecer el statu quo antes de los hechos victimizantes (en este caso en 


\section{Desaparición forzada de compañeros sentimentales}

\section{Significado del proceso de reparación en dos mujeres}

particular la desaparición forzada). La reparación como proceso tiene sus inicios a partir de la Declaración Universal de los Derechos Humanos cuyo artículo 8 establece que toda persona puede hacer uso del recurso de acudir ante los Tribunales cuando les han sido afectados sus derechos fundamentales. Adicionalmente, el Pacto Internacional de Derechos Civiles y Políticos (1966) afirma que "toda persona que haya sido ilegalmente detenida o presa, tendrá el derecho efectivo a obtener reparación". En tanto principio se estableció en la Convención Internacional sobre la Eliminación de Todas las Formas de Discriminación Racial, en la Convención Contra la Tortura y Otros Tratos y Penas Crueles, Inhumanos y Degradantes, en la Convención sobre los Derechos del Niño y en la Convención Internacional para la Protección de Todas las Personas Contra las Desapariciones Forzadas, con un alto estándar de reparación. Igualmente, quedó prescrito en el Protocolo Adicional a los Convenios de Ginebra del 12 de agosto de 1949 relativo a la Protección de las Víctimas de los Conflictos Armados Internacionales (Protocolo I) y en el Estatuto de Roma de la Corte Penal Internacional.

Posterior a estos decretos y declaraciones, una serie de instrumentos internacionales fueron determinados, los cuales son de carácter específico y apuntan a establecer garantías para que los Estados, dentro de sus legislaciones internas, incluyan mecanismos de reparación justa y adecuada.

\section{Mujeres Víctimas}

Cualquier tipo de acción u omisión que genere violencia y que ocasione en la mujer daño físico, sexual, psicológico, económico, así como amenazas de ejercer estos actos convierte a la mujer en víctima (Convención de Belém do Para, Organización de los Estados Americanos, 1995). A lo anterior se suma aquella violencia que suceda en la comunidad y que sea perpetrada o permitida por el Estado o sus agentes donde quiera que ocurra.

\section{Desaparición Forzada de personas}

Es el término jurídico que designa a un tipo de delito complejo que implica la violación de múltiples Derechos Humanos -eg:, el derecho a la vida, a la libertad, a la seguridad e integridad personal, a la justicia y proceso legal, a la libertad de opinión, expresión e información, a los derechos laborales y políticos implicando la consiguiente restricción de actividades religiosas y de Organismos defensores de los Derechos Humanos (Comisión Interamericana de Derechos Humanos, 1979)-. Dicho delito cometido en diversas situaciones constituye un crimen de lesa humanidad.

La desaparición forzada se caracteriza por la privación de la libertad de una persona por parte de agentes del Estado, o grupos o individuos que actúan con su apoyo, seguida del no reconocimiento de dicha privación con el objetivo de marginarla de la protección de la ley. Dicha negativa al reconocimiento de este hecho busca favorecer deliberadamente la impunidad de los responsables quienes, a su vez y tras el mismo fin, intimidan al colectivo social al cual pertenece la persona desaparecida. Los efectos de la desaparición forzada permanecen hasta que no sea resuelta la suerte o paradero de la(s) persona(s) desaparecida(s), prolongando el sufrimiento que se causa a familiares y allegados. Debido a su largo alcance, la desaparición forzada es también definida como un abuso continuo extensivo a la familia de la víctima que sufre no sólo con la ausencia de su ser querido sino con la impunidad de los autores quienes no comparecen ante la justicia. Lo anterior lleva a que, en algún momento, miembros de la familia o allegados padezcan estrés postraumático, así como alteración de su identidad y la imposibilidad de vivir su duelo, entre otros efectos (Amnistía Internacional, 2008).

\section{Compañeros Sentimentales}

A partir del marco legal vigente en Colombia, se denomina unión marital de hecho a la unión formada entre un hombre y una mujer, quienes sin estar casados hacen una comunidad de vida permanente y singular. Asimismo, y para todos los efectos civiles, se denomina compañero y compañera permanente al hombre y mujer quienes forman parte de la unión marital de hecho Congreso de la República (Ley 54 de 1990).

Bowlby (1986) señalaba que los vínculos afectivos forman parte integral del desarrollo del ser humano y describía la vivencia de dichos vínculos como enamorarse, el mantenimiento éstos como amar a alguien y la interrupción o ruptura de estos vínculos como duelo (tras dicha interrupción o ruptura, la renovación de este vínculo genera posibilidad de alegría). Uno de los aspectos más significativos del vínculo afectivo que se establece con los compañeros sentimentales es la comunicación pues constituye uno de los ejes más importantes en la relación afectiva y en la interacción en tanto mecanismo a través del cual se expresan los sentimientos, se brinda información al otro y es el vehículo utilizado en la resolución de problemas, todos aspectos esenciales para la calidad de la relación.

Cabe agregar que el apego que se genera en la pareja da origen a diferentes tipos de expresiones y esquemas culturales y mentales de relación que son interiorizados a través de las experiencias afectivas. Dichas expresiones son manifiestas en forma de comunicación, en el grado de apertura emocional, la valoración que se tiene de uno mismo y de los demás, y afectan directa e indirectamente la vida afectiva personal y relacional del individuo.

\section{Subcategorías}

\section{Legal}

En el ordenamiento jurídico vigente exige unirse al calificativo de principio y extenderse a la vinculación positiva que se tiene con el Estado y que obliga que todos los actos y disposiciones se ajusten al derecho, pues la norma, a más de ser garantista, condiciona y determina de manera positiva las consecuencias a las afectaciones de bienes jurídicos protegidos por el legislador. Bajo este tenor, ha de entenderse el principio de legalidad como el fundamento jurídico en virtud del cual los ciudadanos y todos los poderes públicos están sometidos a las leyes y al derecho. Luego el principio de legalidad implica el fundamento o la base que resguarda a todos los ciudadanos para que se respeten sus derechos y se impongan sanciones solo por las conductas que el legislador haya calificado como punibles y que, al ser delito, conllevan una pena ante el incumplimiento de las obligaciones que los rige (Orduz, 2010).

Tal como lo afirma (García, 2000), el concepto legal corresponde a un valor jurídico cuyo contenido son los valores instrumentales que el derecho genera a quien porte, pero a su vez garantice, derechos y deberes. Refiere a un sistema de valores mediante el cual se quieren 
alcanzar objetivos o ideales como: orden social, igualdad y seguridad, constituyéndose estos en valores superiores que a su vez conducen a la paz social, la libertad y el bien común que llevan a la justicia.

\section{Biológico/Físico}

Según Boentes (2009), lo social se generó a partir de lo biológico, el hombre es el único ser vivo que convive en sociedad y que interactúa constantemente dentro de la misma y, por ende, su salud está condicionada por fenómenos y factores sociales. Éstos fenómenos y factores sociales hacen que el hombre sea percibido no como una unidad biológica aislada sino como un ser biopsicosocial, y que destaque su relación con la naturaleza, con lo ambiental, así como el desarrollo científico técnico alcanzado por la sociedad que le permite actuar en función de sus necesidades y aspiraciones.

\section{Psicológico/Cognitivo emocional}

El término Psicología proviene etimológicamente del griego psique (alma) y logos (tratado, ciencia), literalmente significa 'ciencia del alma'. La Psicología es la ciencia que estudia la conducta y los procesos mentales, trata de describir y explicar todos los aspectos del pensamiento, los sentimientos, las percepciones y las acciones humanas. En la Ley 1090 de 2006:

Definen la Psicología como una ciencia sustentada en la investigación y una profesión que estudia los procesos de desarrollo cognoscitivo, emocional y social del ser humano, desde la perspectiva del paradigma de la complejidad, con la finalidad de propiciar el desarrollo del talento y las competencias humanas en los diferentes dominios y contextos sociales tales como: La educación, la salud, el trabajo, la justicia, la protección ambiental, el bienestar y la calidad de la vida. Con base en la investigación científica fundamenta sus conocimientos y los aplica en forma válida, ética y responsable en favor de los individuos, los grupos y las organizaciones, en los distintos ámbitos de la vida individual y social, al aporte de conocimientos, técnicas y procedimientos para crear condiciones que contribuyan al bienestar de los individuos y al desarrollo de la comunidad, de los grupos y las organizaciones para una mejor calidad de vida.

La Psicología se puede considerar como parte de las Ciencias Humanas o Sociales que estudia el comportamiento de los organismos individuales en interacción con su ambiente, con lo que les rodea, los procesos mentales de los individuos que permiten se perciba ese ambiente y los procesos de comunicación desde lo individual a lo social.

\section{Social/Redes sociales de apoyo}

Las redes sociales son estructuras que permiten a las personas interactuar a través de relaciones basadas en el intercambio emocional y material por medio del cual se ofrece y se obtiene apoyo social. Estas redes de apoyo tienen una alta incidencia en el bienestary la integración social de los individuos en condiciones de vulnerabilidad o afectados por alguna situación en especial (Ávila, 2009). Hobfoll y Stoke (1988) definen las redes sociales como "aquellas interacciones o relaciones sociales que ofrecen a los individuos asistencia real o un sentimiento de conexión a una persona o grupo que se percibe como querida o amada".

En cuanto al apoyo social en (Gracia, 1995) es definido como "El conjunto de provisiones, expresivas o instrumentales, percibidas o recibidas, proporcionadas por la comunidad, por las redes sociales y las personas de confianza, tanto en situaciones cotidianas como de crisis".

De una u otra forma la mayoría de los autores identifican apoyo social con la relación interpersonal en la que se ofrece o intercambia ayuda de tipo material, emocional o instrumental y que produce sensación de bienestar al receptor. Para Caplan (1974), un sistema de apoyo implica un patrón duradero de vínculos sociales continuos e intermitentes que desempeñan una parte significativa en el mantenimiento de la integridad física y psicológica de la persona (efectos protectores): al promover el dominio emocional, al proporcionar orientación y consejo, al proveer ayuda y recursos materiales, y al proporcionar feedback sobre de la propia identidad y desempeño (Gracia, Herrero, \& Musitu, 1995).

\section{Procedimiento}

El procedimiento fue dividido en cuatro (4) etapas: preparación teórica; categorización; técnica de recolección de información; y análisis de la información.

\section{Etapa 1. Preparación teórica}

En esta atapa resulta preciso hacer una aclaración sobre lo que se entiende por historia de vida en distinción a relato de vida, en tanto la primera atañe a la presente investigación. Tal como lo afirman Cornejo et-al. (2008) la historia no se entiende como la construcción total de la experiencia de una persona, sino la que está orientada, de forma exclusiva, a los propósitos y metas de los investigadores. Por su parte, el relato de vida hace referencia a un texto en el que no hay intervención por parte del investigador.

\section{Etapa 2. Recolección de la información}

Antes de llevar a cabo la recolección de datos, se sostuvo una reunión individual con cada una de las participantes para explicarles el propósito de la investigación, el alcance de la información suministrada por ellas y asegurarles que su anonimato estaba garantizando. Durante esta reunión se creó un ambiente seguro y confiable en pro del objetivo del estudio. fases:

La recolección de información se desarrolló en dos (2) siguientes

a. entrevistas individuales con cada una de las participantes, cuya duración fue de hora y media y cuyo eje central y producto final fue la historia de vida de las participantes.

Las historias de vida fueron trascritas de manera textual pues serían el insumo y, como lo afirma (Bogdan, 1986) el elemento principal para la comprensión del objeto de investigación.

b. Identificación de categorías emergentes a partir de los relatos.

\section{Etapa 3. Categorización}

El proceso de categorización obedeció a una estrategia inductiva y deductiva para su identificación final. A este respecto se contó con cuatro (4) categorías generales como categorías deductivas (proceso de reparación; mujeres víctimas; desaparición forzada; y compañeros sentimentales), las que actúan. A partir de estas categorías se formularon 


\section{Desaparición forzada de compañeros sentimentales}

\section{Significado del proceso de reparación en dos mujeres}

preguntas lo suficientemente globales para producir, en consenso con el investigador, una historia de vida que diera cuenta de las experiencias particulares de la participante. Acto seguido se crearon de forma inductiva las categorías resultantes del proceso de construcción de historias de vida (categorías inductivas) las cuales se unificaron de tal forma que fuese posible cruzarlas con las cuatro categorías deductivas iniciales, lo anterior con el fin de guiar la discusión de resultados.

Además de la revisión conceptual, para la construcción de las preguntas orientadoras, se tuvo en cuenta tanto la entrevista desarrollada por Antillon (2008) -sobre la desaparición forzada de Rosendo Radilla- como el modelo de formulación clínica sugerido por Castro (2000), que señala la existencia de una influencia ambiental sobre el comportamiento del individuo al incidir en sus procesos afectivos e interacciones. Sobre estos últimos también influyen significativamente el medio familiar próximo y las relaciones interpersonales, al generar patrones de comportamiento.

\section{Discusión de Resultados}

Con la desaparición forzada se vulneran derechos inherentes al ser humano y aquellos concebidos en la Constitución Política de Colombia. Si bien existe un conjunto de normas dirigidas a restituir los derechos de las víctimas, el proceso de reparación tiene sentido cuando se parte de la realidad de las víctimas, lo que implica considerar la dimensión del daño sufrido. Lo anterior se puede hacer mediante la realización de un peritaje por parte de un psicólogo jurídico, a fin de generar insumos que permitan el fortalecimiento de las políticas criminales en torno a la desaparición forzada y que incluso contribuyan a la creación de nuevos instrumentos jurídicos, como el establecimiento de leyes a ser incluidas en la legislación colombiana.

Entre sus medidas la reparación incluye el restablecimiento de la situación previa de la víctima, así como el regreso a su lugar de origen, la devolución de bienes y empleo. Sin embargo, en el caso particular de las participantes del presente estudio, dichos derechos no fueron restablecidos en tanto las familias víctimas fueron obligadas a abandonar su lugar de origen para preservar su vida y no han podido regresar, situación que imposibilita la devolución de sus bienes y que altera su tejido social.

Una de las medidas más reconocidas en el proceso de reparación es la indemnización entendida como la retribución monetaria por daños y perjuicios materiales y morales (miedo, humillación, estrés), que tiene como objetivo subsanar temporalmente las necesidades básicas de las víctimas. Sin embargo, esta indemnización no tiene un efecto significativo en el contexto individual y familiar además del económico y es finalmente recibida por las víctimas y sus familias tras varios años de lucha y de sortear dificultades económicas que afectan seriamente su calidad de vida y que producen en ellas sentimientos de desesperanza frente al proceso de reparación.

La reparación también contempla la rehabilitación que incluye atención médica y psicológica, sin embargo, las participantes del presente estudio no han disfrutado de un acompañamiento psico-

\section{Etapa 4. Análisis de la Información}

A partir de las categorías generales (mujeres víctimas; desaparición forzada; reparación; y compañeros sentimentales) fueron construidas cuatro (4) subcategorías deductivas (legal/instituciones, biológico/ físico, psicológico/cognitivo/emocional y social/redes de apoyo) antes de llevar a cabo el proceso de recopilación de la información. Adicional a lo anterior, las categorías emergentes fueron consideradas a partir del relato de las participantes.

Los relatos producto de la entrevista fueron transcritos completamente sin omitir rupturas en la narración y el lenguaje, conservando literalmente las expresionesemitidas porlas participantes. Lo anterior con el fin de mantener la idea global del relato y desarrollar el análisis a partir de las categorías y subcategorías identificadas en el mismo. Tras un análisis al texto producto de la transcripción de las historias de las participantes, dichas categorías fueron resumidas de manera progresiva hasta obtener dos (2) categorías inductivas por cada una de las categorías deductivas descritas, para guiar la posterior discusión de resultados. jurídico y psicosocial pleno, incluso desde el momento de la denuncia de desaparición de sus compañeros sentimentales les fueron vulnerados sus derechos, sufriendo así una victimización secundaria durante este proceso.

Dentro de las medidas de reparación también está incluida la satisfacción mediante el restablecimiento de la dignidad y que mitiga el dolor de las víctimas. En la presente investigación se reconoce que tal medida no se cumple en tanto el dolor generado por la desaparición forzada no ha sido subsanado y, por el contrario, durante el proceso de reparación acrecienta el mal trato recibido al tratar de acceder a los mecanismos jurídicos existentes para reportar la desaparición de sus compañeros.

En lo que respecta a la reparación de la memoria se le ha negado tanto a los hijos víctimas como a la sociedad en general el derecho a conocer realmente quiénes eran estas personas desaparecidas, quienes eran a su vez padres, hijos y miembros activos de una comunidad. Las acciones simbólicas de reparación de la memoria deben generarse a partir de las vivencias de las familias de las víctimas -en este caso las compañeras sentimentales quienes a partir de su relato realizan aportes significativos permitiendo reconstruir una memoria simbólica positiva y asertiva de las víctimas, que genere el impacto deseado en su familia y, en especial, en esos seres que no han tenido la oportunidad de amar y proteger: sus hijos.

Un aspecto a destacar en este punto es la dignidad de la persona desaparecida, la cual cobra especial relevancia pues hay que tener presente que las víctimas y sus familias forman parte de un colectivo social que en ocasiones suele estigmatizarlas, algunas veces por temor, por presión ejercida por los actores responsables de la desaparición, o al atribuirles acciones criminales a los desaparecidos. Por esta razón es importante que en el desarrollo de medidas simbólicas se rescate el valor y dignidad de las personas desaparecidas y que se conozca la verdad de los hechos, con miras a un efecto positivo no sólo en el núcleo familiar sino también en el colectivo social.

Loanteriorfacilitael proceso dedueloyconstituye parteimportante de la memoria colectiva arraigando la fuerte convicción que en su colectivo la desaparición forzada es una historia que definitivamente no tiene que repetirse de nuevo, lo cual a su vez va en sintonía una de 
Tabla 3 Categorías Inductivas

Me dio mucho guayabo... me dio de todo... porque ni más nunca supe de él, como en ese entonces no existía la Fiscalía, no existía como ahora... es computadores... nada. En el año 95 no existía nada de eso, entonces ¿uno donde ponía la denuncia? Nada, no 17-(1) existía nada de eso... La UAO, nada de eso existía en ese entonces. Yo lo dejé así, pero Legal cuando salió esa cosa de víctimas y todo eso yo metí la cosa.

( ${ }^{\star}$ AO: Unidad de Atención y Orientación a Población Desplazada).

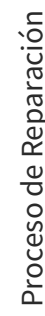
Es que la reparación integral no la ha habido ¿no? Porque eso lleva a lo social, lo eco-
326-(2) nómico, lo colectivo, y nosotros somos un grupo de varias personas que teníamos diferentes aspiraciones respecto a cómo se nos repare.

Porque yo tenía la esperanza de encontrarlo, que él estuviera vivo para encontrarme

Psicológico

Cognitivo

Emocional

487-(1) mande cuando él se graduó y todo eso de $5^{\circ}$, con la esperanza que él llegara algún día y preguntara por él, un día el ir allá o venir acá y ya 20 años como que ya ha pasado mucho.

205- Con el apoyo de mi mamá que representaba para mí para poder trabajar.

Social/Redes de Apoyo

bueno siempre esas personas que han estado a mi lado, mis compañeros, mis amigos, mis parejas han respetado mi deber de búsqueda, han compartido, me han apoyado, me ayuda un poquito hacer un poquito en la labor de búsqueda entonces han sido muy respetuosos en mi deber y mis derechos como esposa de un desaparecido. No después de la desaparición sí sufro de migraña y ahora últimamente no estoy

164- durmiendo casi nada, no sé cómo no estoy vieja si el sueño es vital para uno, y últimamente estoy sufriendo de migrañas.

Biológico/

Físico

Aurora: No, o sea mucho dolor de cabeza, se me prendió mucho el dolor de cabeza, ahora sufro del dolor de cabeza, me toca estar tomando pastillas, una pastilla que se llama cafeína, me mandó el médico.

310- Pues es que yo tal vez la única declaración que recuerdo fue cruel, fue crueldad absoluta, se siente en un banquillo, preguntándole a uno, yo salí con mucho miedo.

\section{Psicológico/}

Cognitivo

Emocional

Legal

Social/

Redes de Apoyo

251-(1)

8-(1)

Eso va cambiando, nosotros primero queríamos que apareciera, después que nos dijeran la verdad, todo eso va sumando, que aparezca y que diga la verdad, luego ahora yo quiero que él no haya durado vivo más de ocho días porque me imagino las torturas y las cosas que debe haber padecido.

Llegaron unos formularios a acción social y yo pedí uno, en esa época llegó un muchacho de la Fiscalía de Cartagena, porque yo mandé un derecho de petición.

Un abogado de Acción Social, yo hice todos los papeles aquí en Bogotá porque m asesoría fue aquí.

Mi mamá me lo ayudada a cuidar y lo metimos a un jardín, los jardines de antes eran hasta las 2:00, ahí lo recogía mi mamá hasta las 4:00 que yo salía.

Cambio extremo, pero como mi mamá siempre estaba ahí, ella me apoyaba, pues no fue tan duro, estaba mi mamá y mis hermanos ahí apoyándome

A mi marido se lo llevaron, llegaron veinte hombres armados y se lo llevaron. No dijeron nada, a mí me dijeron que tenía veinticuatro horas para que desocupara.

Yo mandé un derecho de petición, me dijeron manda un derecho de petición y yo lo mandé a la Fiscalía de aquí, entonces eso lo mandaron a Cartagena porque eso era del sur de Bolívar, porque todo lo que nos pasó fue en el sur de Bolívar. Lo mandaron

422-(1) a Cartagena, entonces vino un señor del CTI de Cartagena y yo le dije todo, yo le conté todo y ese día se llevó eso y dijo que cualquier cosa tenían que llamar al CTI de Cartagena.

Porque yo tenía la esperanza de encontrarlo, que él estuviera vivo para encontrarme con el yo tenía la esperanza que él fuera donde mi abuela y yo le di el teléfono y le mandé cuando él se graduó y todo eso de $5^{\circ}$ con la esperanza que el llegara algún día

Psicológico/ Cognitivo mucho, ya no va a aparecer. Yo le dije la verdad y yo pienso que eso lo ha afectado mucho porque esos son los sueños de los niños: conocer a su padre, como es si es feo, si es alto, si es bajito, los niños son así.

Social/Redes de Apoyo

Psicológico/

Cognitivo

Emocional

Biológico/ Físico
Entonces nosotros nos reuníamos allí, como para hacer qué acciones tomar, hacia

120- dónde ir. Nos íbamos para el CANTÓN NORTE para el CHARRY SOLANO, porque ya ido a todos los hospitales, ya habíamos ido a todos los sitios.

90-(1) Bien, bien, nunca me llegó a maltratar que yo recuerde, que me haya dicho alguna mala palabra tampoco, todo era normal.

106-(1) Los planes era comprar una casa en el pueblo, pero no en el Socorro, en San Pablo Bolívar.

No, porque con él pasé momentos inolvidables, nos íbamos a bañarnos, a pescar, y

608-(1) esos momentos no los he vuelto a pasar otra vez nunca, y el tiempo atrás que se va no vuelve.

81-(1) Salíamos a pescar, íbamos a galapagar.

88-(1)

Uno las coge y salíamos y agarrábamos bultos y las traíamos para la casa y pescábamos y todo. las garantías del proceso de reparación, a saber, aquella de no repetición. En el caso de las participantes de este estudio, el daño sufrido a nivel colectivo y el temor de la comunidad a las represalias impidió que tras la desaparición de sus compañeros sentimentales estos colectivos fuesen solidarios y les brindaran el apoyo necesario cuando quedaron solas. Entonces, esta garantía de no repetición resulta fundamental en tanto brinda seguridad al colectivo y a la comunidad, lo que a su vez posibilita una mayor apertura y mayor aceptación hacia las víctimas y sus familias. Lo anterior fomenta la reconstrucción de lazos familiares y sociales, y permite que los miembros de la comunidad constituyan redes de apoyo económicas y emocionales que faciliten la adaptación de estas mujeres y sus familias nuevamente a la sociedad.

La educación como medida de reparación tampoco se cumplió en los casos de éstas mujeres -a diferencia del caso de la Róchela- en tanto sus hijos no han logrado tener un acceso privilegiado a la educación -ni la salud-, lo que los obliga a someterse a largas jornadas de trabajo para poder generar los recursos necesarios para sufragar sus gastos académicos. Ellas consideran que una verdadera reparación debe garantizar la educación a los hijos víctimas de la desaparición forzada de sus padres y debe brindarles oportunidades de trabajo estables. Como lo señala un viejo proverbio chino: "educar es trascender, acceder a una educación de calidad brinda la posibilidad de obtener mejores oportunidades laborales y mejor remuneradas, permite desarrollar habilidades que contribuyen al logro de proyectos de vida individuales y familiares, y conduce a una mayor calidad de vida. Adicionalmente, la educación dota a los individuos de conocimiento sobre sus derechos y la defensa de los mismos, lo que reduce la impunidad.

A pesar que en la sentencia T/556 de 1998 se menciona que el ser humano es único y diferente lo que llevaría a considerar las necesidades particulares de cada caso como no- generalizables y requiriendo un tipo de acción específica, en la praxis el Estado no concibe los casos desde una perspectiva diferencial respecto las personas afectadas, lo que impide una verdadera reparación a las mujeres víctimas de la desaparición forzada de sus compañeros y e impide una reparación a las familias, pues no 


\section{Desaparición forzada de compañeros sentimentales}

\section{Significado del proceso de reparación en dos mujeres}

se considera el impacto de la desaparición en el núcleo familiar (las afectaciones al bienestar físico, emocional, mental y social).

Durante la fase inicial de desaparición forzada las familias se ven abocadas a cambios constantes que dificultan la obtención de fuentes de ingreso que les permitan vivir de manera digna, por lo que uno de los derechos que no es reconocido ampliamente en el proceso de reparación es la dignidad.

En el caso de los hijos víctimas de la desaparición de su padre, los vacíos producidos por su ausencia los perciben en diversos momentos de su vida, siendo más profundos en el periodo de la adolescencia porque en esta etapa los padres suelen brindar pautas que permiten a los hijos comprender normas y adquirir valores que les ayudarán para integrarse a la sociedad e incluso a formar una familia en el futuro.

En el caso específico de las mujeres se altera de manera abrupta el rol que solían desempeñar antes de la desaparición de sus compañeros sentimentales (el rol de amas de casa receptoras del soporte económico que ellos brindaban) en tanto se ven obligadas a trabajar en temporales, se convierten en madres cabeza de familia, económicamente responsables de sus familias y principales responsables del soporte emocional y crianza de sus hijos e hijas. Este cambio de rol repentino genera en ellas ansiedad pues han perdido al compañero sentimental que les permitía sentirse protegidas, disfrutar sus derechos sexuales y reproductivos, y que a su vez suplía sus necesidades básicas y las de sus hijos. Estas situaciones y emociones las llevaron, en ocasiones, a buscar refugio en otras parejas con quienes la relación no fluyó igual que con sus compañeros desaparecidos, pues fueron sometidas a violencia emocional y física.

Tal sobrecarga afectiva, económica y social incide de manera negativa sobre el derecho de estas mujeres a decidir y reconstruir su propia vida, pues se les dificulta el proceso de reconstrucción personal al llevar sobre sus hombros el peso de la reconstrucción de un tejido social y familiar fracturado Solano (2004) y se les vulnera la libertad de elegir profesión u oficio, lo cual va en contravía del artículo 26 de la Constitución Política de Colombia (1991) que señala que toda persona es libre de escoger profesión u oficio.

Particularmente, entonces, el equilibrio emocional de las mujeres participantes deesteestudio sevio afectado y, como lo menciona Castex (2003), sus esferas afectiva, intelectiva y volitiva se ven afectadas lo que limita su capacidad de disfrutar de diversos contextos como el familiar, laboral y social, y constituye un daño psicológico. Sufrieron alteraciones en su estructura psicosomática -como aquellas mencionadas por Fernández (1993)- pues generaron dolencias constantes a nivel físico (dolor de cabeza) a partir de la desaparición de sus compañeros y debido a la incertidumbre de sus paraderos. El dolor que sienten por la ausencia de su compañero ha producido en ellas pesadillas repetitivas que incluso les han causado depresión y trastornos del sueño (como el insomnio).

Estas mujeres se vieron obligadas a abandonar sus recuerdos y su ciudad de origen para llegar a otros sitios extraños con personas desconocidas. Allí tuvieron que enfrentar la indiferencia y dificultades al momento de relacionarse con las personas que integraban la comunidad local, lo que minó la generación de nuevas redes de apoyo (éstas se redujeron únicamente al entorno familiar) y, con ello, la posibilidad de expresar el dolor e incertidumbre que las agobia. Según su relato, ellas decidieron ocultar sus recuerdos y callar su condición -y la de sus hijos- de víctimas porque temían ser estigmatizadas en su nueva comunidad, no querían ser consideraras un riesgo.

Además, debido a la falta de sentido de pertenencia, les fue difícil adaptarse a las exigencias y costumbres de los locales, por ejemplo, la imposibilidad de preparar los alimentos de la misma manera que lo hacían en su lugar de origen afectó su calidad de vida en términos alimenticios y también tuvo repercusiones en aspectos como su identidad.

Otro aspecto que ellas enfatizan en su relato, es la afectación al proyecto de vida, tanto los personales como los que habían planeado en pareja (la posibilidad de que ellos y sus hijos accedieran a estudio, la adquisición de una vivienda propia, entre otros). Estos proyectos se alteraron drásticamente al cambiar sus prioridades, pues prevalecía -y aún prevalece- salvaguardar su integridad como mujeres -y la de sus hijos- y, por consiguiente, los sueños individuales pasaron a un segundo plano. Tal afectación tiene gran magnitud y alcance, pues repercute en el sentido de vida que brinda al ser humano tener un interés frente a unas metas y propósitos a lo largo de su desarrollo vital, como lo afirma Colorado (2014), "el daño al proyecto de vida es mucho más amplio, porque se refiere al proyecto, no como parte de la vida, sino como un daño a la vida misma. De lo anterior queda que, dentro de los mecanismos de reparación establecidos, se debería tomar en mayor consideración este daño que afecta seriamente la existencia de estas mujeres y la de sus hijos.

Los resultados obtenidos por el grupo investigador indican que estas dos mujeres no se consideran reparadas en su totalidad, que sienten descontento e insatisfacción respecto al restablecimiento de sus derechos y que, tras del hecho, padecen victimización secundaria. De lo anterior se sigue que las pocas acciones simbólicas de reparación implementadas han resultado superficiales e insuficientes. Dado que el daño sufrido por la desaparición forzada de sus compañeros constituye una huella indeleble e irreparable, como lo afirma Gaona (2009), la reparación puede ser percibida como una acción que no repara. Evidenciar, a través de sus relatos, la magnitud del daño sufrido ha permitido identificar las limitaciones del proceso de reparación y aquellas del enfoque diferencial de género y de inclusión.

Es entonces necesario pasar de la visión de restitución como reposición de un activo económico exclusivamente hacia un enfoque verdaderamente reparador y transformador que reconozca y conozca a las víctimas a partir de sus realidades específicas, como parte de una comunidad que debe ser reconstruida y transformada para así garantizarles a las víctimas que puedan desarrollar sus capacidades y aplicar sus habilidades con el fin de constituirse como agentes de su propia vida y de la vida social y política de sus comunidades. Este enfoque debe además reevaluar el aspecto de generalización de medidas a todas las víctimas, pues es necesario tener presente que cada ser humano es único e irrepetible, y asimismo lo es su sufrimiento.

Las limitaciones o retos expuestos se deben a que los vacíos generados por la desaparición del compañero sentimental sobrepasan los aspectos materiales y obstaculizan la construcción de un proyecto de vida, el empoderamiento por la lucha de sus derechos y el desarrollo de estrategias de afrontamiento que les permitirán a las mujeres víctimas enfrentar mejor esté difícil capítulo de su vida y hacer la transición de víctimas a sobrevivientes políticamente activos, con capacidad de hacer contribuciones a la creación de políticas públicas en torno a la desaparición forzada.

Además, en el proceso de restitución el Estado y la Sociedad tienen el deber de apoyar a estas mujeres víctimas, garantizando el ejercicio pleno de sus derechos y los de sus hijos e hijas, pues sus derechos no son garantizados. Sin embargo, a pesar de las falencias, estas mujeres consideran al Estado como un ente benefactor para con ellas, pero consideran que su interés debería ser la satisfacción de los derechos a la verdad, la justicia y la reparación integral, aunque estos 
dependan de una situación voluntariosa por parte del gobierno de turno. El Estado, bajo un verdadero estado de derecho, debe asumir la implementación de procedimientos y garantías indispensables para obtener de manera eficaz, ágil y rápida los recursos necesarios para la ejecución de mecanismos de reparación, sin que esta esté sujeta al rubro presupuestal del Estado.

También resulta necesario tener en cuenta que las medidas simbólicas como mecanismos de reparación no son extensivas a todas las víctimas puesto que el significado difiere para cada familia. Sin embargo, deben dirigirse a todas las víctimas en tanto constituyen un mecanismo de difusión que permite la divulgación de los sucesos vividos por estas mujeres, permiten evidenciar la magnitud y alcance de estos delitos y el reconocimiento de las graves violaciones de Derechos Humanos sufridas tanto por ellas y sus compañeros sentimentales, como sus hijos y el colectivo social al que pertenecen. Lo anterior se debe a que experienciar, compartir y se recordar de manera colectiva genera un ambiente de solidaridad, insumo importante en la reconstrucción del tejido social.

Otra medida importante contemplada en la ley de reparación pero que no es de cumplimiento obligatorio, a pesar que debería serlo, es la localización de los restos de los desaparecidos. Desconocer la ubicación de sus restos condena a las parejas, hijos, demás familiares y allegados a la imposibilidad de vivir su duelo y a una incertidumbre constante las ha acompaña desde el momento de la desaparición. En sus relatos, las mujeres participantes comentan que durante los primeros días esperaban recibir noticias o encontrar los restos de sus compañeros en los caminos cercanos a su lugar de vivienda o trabajo, después esperaban recibir noticias por parte de los miembros de su comunidad o, en su defecto, de los organismos responsables de la investigación. Pero pasan los años y, como lo señala Beristaín (2008), estos sentimientos de duelo quedan congelados en el pasado; esa oportunidad de cierre continúa suspendida en el tiempo y mientras éste transcurre se preguntan si fueron torturados, si sufrieron mucho. ¿Acaso no es un derecho inalienable de estas mujeres poder realizar los rituales fúnebres de sus seres queridos? Como lo mencionan las participantes, el derecho a la verdad y a la localización de los restos de sus compañeros debe ser una prioridad.

Tomando en consideración lo expuesto hasta el momento, resulta evidente la importancia del rol del psicólogo jurídico pues, por un lado, puede crear programas de formación en Derechos Humanos que brinden a las víctimas conocimiento sobre sus derechos y, por consiguiente, herramientas jurídicas existentes para la defensa de los mismos; por otro lado, pueden realizar peritajes forenses que trasciendan el informe clínico, poniendo en evidencia la dimensión real del daño psicológico producido en las víctimas de desaparición forzada (como es el caso de las dos mujeres participantes de esta investigación) y en su núcleo familiar y colectivo social y/o comunidad. A través de dicho peritaje estas mujeres víctimas tienen la posibilidad de verbalizar su sufrimiento y revelar el daño sufrido, la posibilidad de constituirse como sujetos activos en la búsqueda de la verdad tras abandonar el rol pasivo atribuida a este género a través de la historia, y la posibilidad de ejercer acciones trasformadoras sobre su realidad. Esto va en consonancia con la necesidad que las participantes manifestaron de ser involucradas en todas las etapas del proceso de restitución de derechos pues, como lo afirma la jurisprudencia de la corte, la víctima es una verdadera parte procesal que tiene plenas facultades de actuar en forma activa durante la investigación.

Tal labor del psicólogo jurídico constituye un insumo de gran valor en tanto contribuye, como lo afirma Mendoza (2013), a la construcción y fortalecimiento de las políticas criminales que pueden hacer frente a este flagelo, puesto que permitirá valorar jurídicamente el daño sufrido, y así proceder de manera asertiva a su reparación, la cual se desarrollará a partir del sentir y las necesidades de las víctimas y sus familias, mas no a partir de una generalización de las víctimas como ocurre actualmente.

En esta medida es fundamental que el psicólogo jurídico promueva desde su disciplina este tipo de investigaciones, que realice aportes que contribuyen significativamente al restablecimiento de derechos de las víctimas y sus familias, y que ponga en evidencia la dimensión del daño psicológico y psicosocial ya que casos como los que atañe esta investigación se prioriza el tratamiento a la salud física, relegando a un segundo plano la salud mental de las víctimas.

A pesar de todas las falencias y retos, en sus relatos estas mujeres destacaron el apoyo recibido de parte de organizaciones conformadas por las víctimas, apoyo que se percibe en educación sobre el reconocimiento de sus derechos -lo que eventualmente las transforma en promotoras de los mismos-y desarrollo de estrategias de afrontamiento (que les permite constituirse como mujeres resilientes, empoderadas y con iniciativa para movilizarse por una verdadera restitución de derechos y por la integración de otras mujeres víctimas a estas organizaciones, para que juntas luchen por la verdad, por la implementación de políticas públicas-desde lo jurídico- que posibiliten un verdadero resarcimiento, justicia y reparación acorde a la realidad y necesidad de las víctimas y sus familias).

Finalmente, se concluye que el significado de reparación para estas mujeres víctimas de la desaparición forzada de sus compañeros sentimentales es aquel de oportunidad de restitución de sus derechos, y que éste debe desarrollarse a partir de su experiencia y debe constituir una constante búsqueda de la verdad y del paradero de sus compañeros quienes un día fueron alejados de manera involuntaria, a quienes les fue vulnerado el derecho a la vida, causando dolor en sus familias.

\section{Referencias}

Amnistía Internacional. (2008). La población civil víctima del conflicto armado interno en Colombia. España: Editorial Amnistía Internacional.

Antillon, X. (2008) La desaparición forzada de Rosendo Radilla en Atoyac de Álvarez. Informe de afectación psicosocial, México, Comisión Mexicana de Defensa y Promoción de los Derechos Humanos.

Asamblea Nacional Constituyente (2009). Constitución Política de Colombia de 1991. Gaceta Constitucional No. 116 de 20 de julio de 1991. Disponible en la página oficial de la Secretaria del Senado del Congreso de la República de Colombia: http://www.secretariasenado.gov.co/senado/basedoc/cp/ constitucion_politica_1991.html

Ávila, J. (2009). Redes Sociales, Generación de apoyo social ante la pobreza y calidad de vida. Colombia.

Bastidas, M., Rodríguez, C., \& Soto, P. (2001). Expresión de la Transgeneracional del Daño: en una muestra de personas afectadas por terrorismo de estado en Chile. Chile: Universidad Central: Tesis de Psicología.

Beristaín, C. (2010). Manual sobre perspectiva psicosocial en derechos humanos. España: Editorial Hegoa.

Biedermann, N. (2009). Detenidos desaparecidos: consecuencias para la segunda generación. En CINTRAS (Ed.), II seminario de la región del Maule: Derechos humanos, salud mental, atención primaria: desafío regional (pp. 170-176). Santiago: CINTRAS.

Brinkmann, B., Guzmán, J. M., Madariaga, C., \& Sandoval, M. (2009). Daño transgeneracional en descendientes de sobrevivientes de tortura. En M. Lagos, V. Vital, B. Brinkmann \& M. Scapucio (Eds.), Daño transgeneracional: consecuencias de la represión política en el cono sur (pp. 15-146). Santiago: LOM Ediciones.

Bowlby, J., (1986). Vínculos afectivos, formación, desarrollo y pérdida. Madrid. Ediciones Morata. 


\section{Desaparición forzada de compañeros sentimentales}

\section{Significado del proceso de reparación en dos mujeres}

Bogdan, R. (1986) La entrevista en Profundidad. En: Introducción a los métodos cualitativos de investigación. La búsqueda de significados. Capítulo 4 Buenos Aires: Paidós.

Bolívar, A. (2002). El estudio de caso como informe biográfico narrativo. Arbor CLXXI, 675 (Marzo), 559-578 pp. Madrid.

Cabanillas Sáenz, (2005). La desaparición forzada como modalidad represiva central de la guerra psicológica en un contexto de terrorismo de estado. Miedo, silenciamiento colectivo y trauma psicosocial. El caso de la dictadura militar de A. Pinochet en Chile. 1973-1990. Bilbao.

Cabrera, M.L. (2006). Violencia e impunidad en comunidades mayas de Guatemala. La masacre de Xamán desde una perspectiva psicosocial. Guatemala: ECAP

Caplan, G. (1974). Support Systems and community mental health. Nueva York: Basic Books

Castex, M. (2003). El daño en psicopsiquiatria forense. Ed. Ad-hoc. Buenos Aires,

Castro, L. (2000). Implicaciones del modelo de formulación clínica para la investigación aplicada y la práctica clínica. Colombia: Universidad de los Andes.

Centro de Salud Mental y Derechos Humanos. (2009). Daño transgeneracional: Consecuencias de la represión política en el cono sur (13-139). Santiago, Chile.

Centro de Salud Mental y Derechos Humanos Cintras (2009). Daño transgeneracional en descendientes de sobrevivientes de tortura. En CINTRAS, EATIP, GTNM/RJ, SERSOC (ed.), Daño transgeneracional: Consecuencias de la represión política en el cono sur (13-139). Santiago de Chile: Sersoc

ICTJ. (2015). Las desaparecidas y las invisibles: Repercusiones de la desaparición forzada en las mujeres. ICTJ, Centro Internacional para la Justicia Transicional. Recuperado de: https://www.ictj.org/sites/default/files/ICTJ Global-Desapariciones-Genero-2015-ES.pdf

Cisterna, F. (2005). Categorización y triangulación como procesos de evaluación. Volumen 14 p. 66. Chile: Dolmen

Colorado, F. (2014). La justicia desde las víctimas perspectiva psicojurídica y victimologica. California edit. Bogotá-Washington-Londres.

Convención Interamericana para Prevenir, Sancionar y Erradicar la Violencia contra la Mujer Convención Belem do Para, (1995). Art. 1.

Convención Interamericana sobre Desaparición Forzada de personas (1994). Desaparición forzada de personas. Recuperado de: https://www.cejil.org/es/ convencion-interamericana-desaparicion-forzada-personas.

Cornejo, M., Rojas, R.C., \& Mendoza, F. (2008). La investigación con relatos de vida: pistas y opciones del diseño metodológico. 17, 29-39. Recuperado de: http://psicologia.uc.cl/profesores-planta./marcela-cornejo-cancino

Elliot, J. (1990) La investigación-acción en educación. Madrid: Morata

Diaz, D. (2011). Transgeneracionalidad del Trauma Psicosocial en descendientes de afectados por la represión política en Chile. (Tesis de grado). Universidad Central. Santiago, Chile.

Fernández, S. C. (1993). Protección a la persona. En: Adorno-Cifuentes y otros, Daño y protección a la persona humana. Buenos Aires: La Rocca,

Gaona, Y. (2009). Estudio exploratorio descriptivo sobre contenidos subjetivos asociados a la restitución, indemnización, rehabilitación, satisfacción y garantías de no repetición (reparación) en familiares y sobrevivientes de violaciones de derechos humanos en chile. Tesis de maestría publicada. Universidad de chile, Santiago de Chile.
Gracia E, Herrero J., \& Musitu, G. (1995). El Apoyo Social. Barcelona, PPU.

Gómez, S.M. (2006), Voces de memoria y dignidad. Recuperado de: http:// personalidadenduelo.wordpress.com/

Hobfoll, S., \& Stokes, J. (1988). The processes and mechanics of social support.2, 29-37. New York: British Journal of Social Work

INMLCF (s.f.). Sistema de Información Red de Desaparecidos y Cadáveres (SIRDEC) INMLCF, Instituto Nacional de Medicina Legal y Ciencias Forenses. Recuperado de: http://sirdec.medicinalegal.gov.co:8083/sirdec/main/ politicas.jsp

INMLCF (2011), Estadísticas de desaparición forzada. Bogotá DC: INMLCF, Instituto Nacional de Medicina Legal y Ciencias Forenses

INMLCF (2016), Observatorio de Violencia, Desaparecidos en Colombia y Nacionales en el Extranjero. Bogotá: INMLCF, Instituto Nacional de Medicina Legal y Ciencias Forenses. Recuperado de: http://www. medicinalegal.gov.co/documents/20143/130741/10-Desaparecidos+Tabler os+A\%C3\%B1o+2016.xlsx/6bab178a-6e72-771a-aedd-56576716d0d4

Ley 54 de 1990. Por la cual se definen las uniones maritales de hecho y régimen patrimonial entre compañeros permanentes. Congreso de la República. Diario Oficial 39.615 de diciembre 28 de 1990.

Madariaga, C. (2003). Daño transgeneracional en Chile. Apuntes para una conceptualización. Reflexión, 30, 11-16.

Mejía, A. (2010), La violencia en Colombia. Bogotá: Colcultura.

Mendoza, S. (2013). Desaparición forzada un delito que trasciende en el tiempo. Ensayo desarrollado para la asignatura Psicología jurídica en el contexto internacional y nacional. Universidad Santo Tomás, Bogotá.

Observatorio de Derechos Humanos y Derecho Humanitario (2012), La desaparición forzada en Colombia. En búsqueda de la justicia. Bogotá: Mesa de trabajo sobre desaparición forzada de la Coordinación ColombiaEuropa-Estados Unidos Bogotá.

ONU. (2009). Guía para la Protección de las personas contra la desaparición forzada. Convención Internacional para la Protección de Todas las Personas contra la Desaparición Forzada. ONU, Organización de las Naciones Unidas. Recuperado de: www.apdh-argentina.org.ar/sites/default/ .... desaparicion-forzada 0

ONU. (2009). Protección de todas las personas contra las desapariciones forzadas. Convención Internacional para la Protección de Todas las Personas contra la Desaparición Forzada. ONU, Organización de las Naciones Unidas. Madrid: Alianza Editorial.

Potter, J., \&Wetherell, M. (1987). Discourse and Social Psychology. London: Sage

Resolución 60/147. (2005). Organización de Naciones Unidas. Obtenido de: http://www2.ohchr.org/spanish/law/reparaciones.htm

Scapusio, M. (2006). Transgeneracionalidad del daño y memoria.32, 15-19. Chile: Revista Reflexión Derechos Humanos y Salud Mental

Sentencia T-556/98. (1998). Derecho a la Salud del Niño-Fundamental/ Prevalencia de Derechos del Niño. Corte Constitucional de Colombia. Sala Plena. Expedientes acumulados Nos. T-160138 y T-168723. Magistrado Ponente. José Gregorio Hernández Galindo. Recuperado de: http://www. corteconstitucional.gov.co/relatoria/1998/T-556-98.htm

Rakoff, V., Sigal, J., \& Epstein, N.B. (1966). Children and Families of Concentration Camp Survivors. Vol. XIV, N 4. Canada's: Mental Health,

Solano, Y. (2004). Procesos de resistencia y reconstrucción colectiva emprendidos por mujeres desplazadas por la violencia en Colombia. Recuperado de http://polis.revues.org/7278;DOU:10.4000/polis.7278

Wodak, R., Meyer, M., (2003). Una Mirada Crítica al análisis del discurso. España 